\title{
Recent Advancement on Current Trend in the Management of Endocrine Emergency in Critically Ill Patient
}

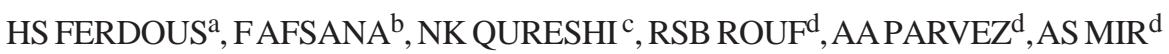

\section{Summary:}

Endocrine emergencies represent a group of potentially lifethreatening conditions that are frequently overlooked, resulting in delays in both diagnosis and treatment, factors that further contribute to their already high associated mortality rates. Although endocrine emergencies are often encountered in patients with a known endocrinopathy, the emergency may be the initial presentation in previously undiagnosed individuals. If these endocrine disorders are not rapidly identified or if specific treatment is delayed, significant complications or even death may occur. Careful

\section{Introduction:}

Diabetic and endocrine emergencies are traditionally treated by the acute medical admitting team or ICU staff. Most will see diabetic emergencies on a regular basis, as they are common and diabetes is increasing in prevalence. Diabetic emergencies are usually easily treated and the patients discharged. However, it is vital not to become complacent as these disorders can lead to death. It is particularly important to follow local guidline and to involve the diabetes team both during and after each episode. The other endocrine emergencies are less common, but in some ways more important simply because of their rarity. A high level of suspicion is often required to make a diagnosis,

a. Dr. HS Ferdous, Senior Consultant, Department of Endocrinology, BIRDEM

b. Dr. Faria Afsana, Registrar, Department of Endocrinology, BIRDEM

c. Dr. Nazmul Kabir Qureshi, Specialist, Department of Medicine \& Endocrinology, United Hospital Limited,

d. Dr. Rushda SB Rouf, Dr. AA Parvez, Dr. AS Mir, Senior Medical Officer, Department of Endocrinology, BIRDEM

Address of Correspondence: Dr. H.S. Ferdous, Senior Consultant, Department of Endocrinology, BIRDEM Email: dr_hsferdous@gmail.com

Received: 8 April, 2015

Accepted: 10 June, 2015 evaluation of clinical history and a high degree of suspicion are the corner stone to diagnose such problems. Aggressive management of the patient is equally important as the complications are devastating and can prove highly fatal. The present article is an attempt to review some of the common endocrine emergencies in intensive care unit and the challenges associated with their diagnosis and management.

Keywords: Endocrine emergencies, Critically ill, Evaluation, Management.

(J Banagladesh Coll Phys Surg 2015; 33: 146-155)

although some, such as acute adrenal insufficiency, myxoedema coma, are usually obvious. In some instances treatment must be started before the diagnosis can be confirmed.

\section{Hypoglycemia:}

Common causes of hypoglycemia in the ICU setting include sepsis, severe hepatic dysfunction, renal failure, and adrenal insufficiency. Administration of excessive exogenous insulin is another common cause. Uncommon causes include pancreatic islet-cell tumors, various nonpancreatic neoplasms (eg, hepatoma, sarcoma, lymphoma, leukemia, and carcinoid tumors) that secrete insulin-like factors, hereditary fructose intolerance, and glycogen storage disease. Certain drugs, (eg, ethanol, sulfonylurea agents, adrenergic blocking agents, pentamidine, quinidine, and disopyramide) can potentially cause hypoglycemia. ${ }^{1}$

\section{Clinical presentation:}

The clinical findings of hypoglycemia are mainly either manifestations of the resulting hyperadrenergic state or the effects of neuroglycopenia. The latter include: headache, visual disturbances, confusion, behavioral changes, delirium, stupor, coma, or seizures. Among the hyperadrenergic manifestations are tremulousness, 
anxiety, diaphoresis, palpitations, tachycardia, nausea, vomiting, and weakness. ${ }^{1,3}$ These signs and symptoms can be absent or blunted in patients taking $\alpha$-adrenergic blocking agents. In most cases the etiology is apparent or the episode represents an isolated event.

\section{Laboratory investigations}

Hypoglycaemia is arbitrarily defined as blood glucose level $<3.9 \mathrm{mmol} / \mathrm{dl}$. However, serial glucose monitoring is very essential to diagnose and treat any such episode in the ICU.

\section{Therapeutic management}

In case of severe hypoglycemia or patients on long acting OAD or insulin even with less severe hypoglycemia require hospitalization. Treatment with I/V glucose and patient education regarding prevention of further hypoglycemia is the cornerstone of management. ${ }^{2}$ Initial treatment consists of IV injection of concentrated dextrose (usually $50 \mathrm{~mL}$ of $50 \%$ dextrose solution). Whatever caused the hypoglycemia is likely to still be present and the hypoglycemia is expected to recur once the dextrose administered has been metabolized. Therefore, a continuous IV infusion of dextrose should be started. The final aspect of acute management is to provide for serial blood or serum glucose testing to detect possible recurrences and tailor the rate of ongoing dextrose administration.

\section{Diabetic ketoacidosis (DKA) and the hyperglycemic hyperosmolar state (HHS)}

Diabetic ketoacidosis (DKA) and the hyperglycemic hyperosmolar state (HHS) appear as 2 extremes in the spectrum of diabetic decompensation. ${ }^{4}$ They remain the most serious acute metabolic complications ofdiabetes mellitus and are still associated with excess mortality.Because the approach to the diagnosis and treatment ofthese hyperglycemic crises are similar, we have opted to address them together.

\section{Pathophysiology:}

\section{Precipitating factors}

Infection remains the most important precipitating factor in the development of DKA and HHS. In 20\%-25\% of cases,infections are the first manifestations of previously undiagnosed diabetes mellitus. ${ }^{5}$ Omissions or inadequate insulin doses are frequent precipitating factors, particularly for DKA. ${ }^{6}$ Other precipitating factors, especially for HHS, are silent myocardial infarction, cerebrovascular accident, mesenteric ischemia, acute pancreatitis and use of medications such as steroids, thiazide diuretics, calcium channel blockers, propranolol and phenytoin. ${ }^{7}$ In $2 \%-10 \%$ of cases of DKA, no obvious precipitating factor can be identified. ${ }^{5}$

\section{Diagnosis and Clinical presentation}

Adefinitive diagnosis of DKA or HHS must be confirmed through laboratory investigation. The clinical presentation can provide helpful information for the preliminary bedside diagnosis. ${ }^{8}$ DKA usually occurs in younger, lean patients with type 1 diabetes and develops within a day or so, whereas HHS is more likely to occur inolder, obese patients with type 2 diabetes and can take days or weeks to fully develop. In addition, HHS usually occurs in elderly diabetic patients, often those with decreased renal function who do not have access to water. ${ }^{9}$ In both conditions, abdominal pain with nausea and vomiting can develop owing to acidosis per se or to decreased mesenteric perfusion and can be mistaken for an acute surgical abdomen. KussmaulKien respiration (rapid and deep respiration)with breath acetone is typical of DKA but is absent in HHS. DKA and HHS are usually accompanied by hypothermia, a normal or elevated temperature may indicate underlying infection.

\section{Laboratory findings}

Table-I
Typical water and serum electrolyte deficits at presentation in DKA and HHS ${ }^{10,11}$

\begin{tabular}{lcc} 
Parameter & DKA & HHS \\
\hline Water, mL/kg & $100(7 \mathrm{~L})$ & $100-200(10.5 \mathrm{~L})$ \\
Sodium, mmol/kg & $7-10(490-700)$ & $5-13(350-910)$ \\
Potassium,mmol/kg & $3-5(210-300)$ & $5-15(350-1050)$ \\
Chloride, $\mathrm{mmol} / \mathrm{kg}$ & $3-5(210-350)$ & $3-7(210-490)$ \\
Phosphate, $\mathrm{mmol} / \mathrm{kg}$ & $1-1.5(70-105)$ & $1-2(70-140)$ \\
Magnesium, mmol/kg & $1-2(70-140)$ & $1-2(70-140)$ \\
Calcium, mmol/kg & $1-2(70-140)$ & $1-2(70-140)$ \\
\hline
\end{tabular}


Table-II

\section{Laboratory diagnostic criteria for DKA and HHS ${ }^{10,11}$}

\begin{tabular}{lccc} 
Parameter & Normal range & DKA & HHS \\
\hline Plasma glucose level, mmol/L & $4.2-6.4$ & $\geq 14$ & $\geq 34$ \\
Arterial $\mathrm{pH}^{*}$ & $7.35-7.45$ & $\leq 7.30$ & $>7.30$ \\
Serum bicarbonate level, $\mathrm{mmol} / \mathrm{L}$ & $22-28$ & $\mathrm{~d}$ ”15 & $>15$ \\
Effective serum osmolality, mmol/kg & $275-295$ & $\leq 320$ & $>320$ \\
Anion gap, $\dagger \mathrm{mmol} / \mathrm{L}$ & $<12$ & $>12$ & Variable \\
Serum ketones & Negative & Moderate to high & None or trace \\
Urine ketones & Negative & Moderate to high & None or trace \\
\hline
\end{tabular}

*If venous $\mathrm{pH}$ is used, a correction of 0.03 must be made.20

†Calculation: $\mathrm{Na}+-(\mathrm{Cl}-+\mathrm{HCO} 3$

\section{Management}

The success of treatment of DKA and HHS depends on adequate correction of dehydration, hyperglycemia, ketoacidosis and electrolyte deficits 24 (Fig. 1). Any comorbid precipitating event should be identified and treated appropriately.

\section{Thyrotoxic crisis:}

The thyrotoxic crisis, or thyroid storm, is a life threatening exacerbation of the hyperthyroid state characterized by decompensation of one or more organ systems. ${ }^{12}$ Usually it complicates Graves disease, but sometimes it occurs in association with toxic nodular

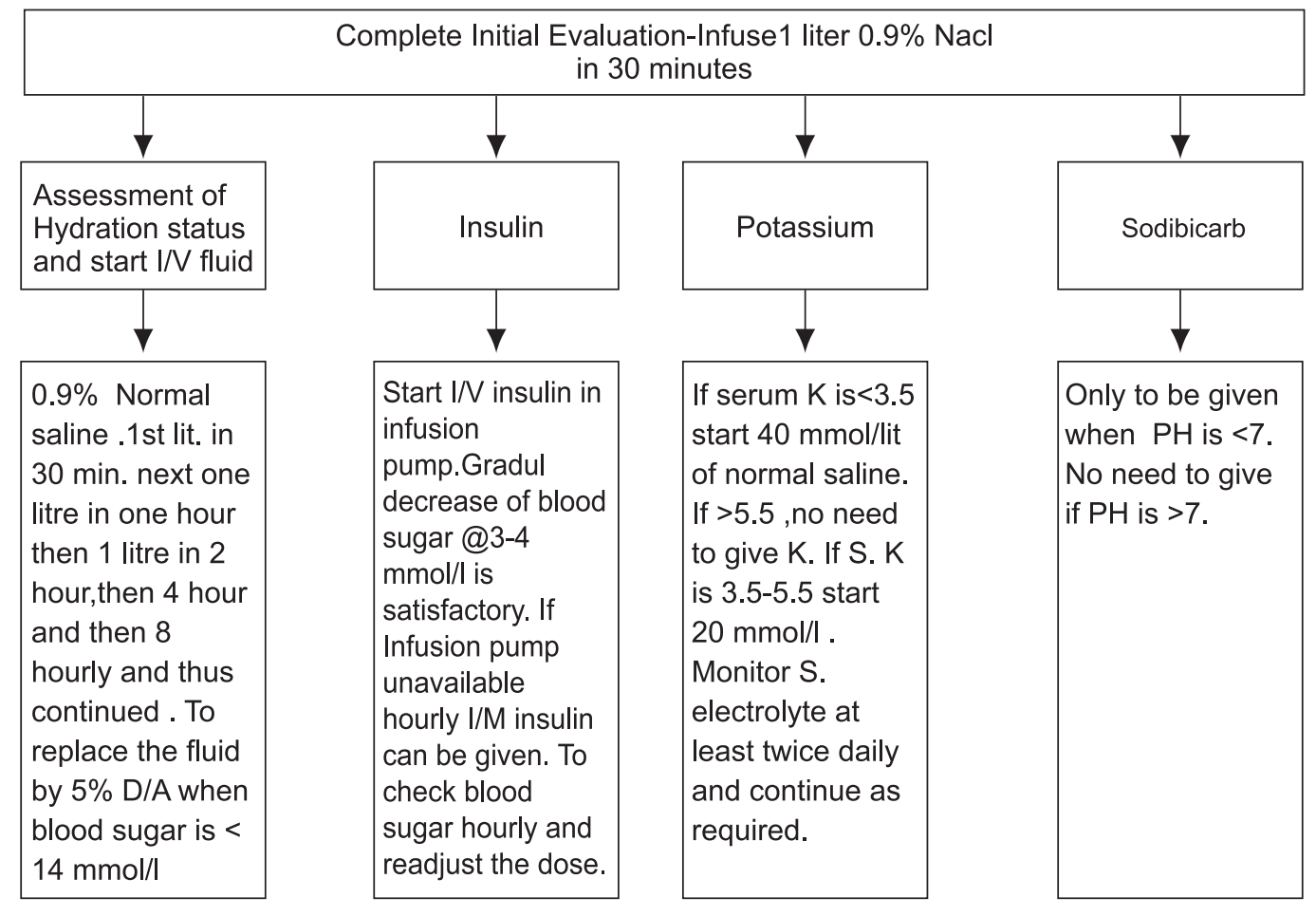

Fig.-1: Evaluation and management of DKA and HHS 
goiter. There is no clear cut off value of circulating thyroid hormones $(\mathrm{TH})$ defining the thyroid storm, since the results of laboratory tests show, in most cases, similar serum levels of $\mathrm{TH}$ to those observed in uncomplicated thyrotoxicosis. ${ }^{13}$ Nevertheless, the rapid recognition of the thyrotoxic crisis and the institution of immediate drug therapy is important in limiting the morbidity and mortality associated with this condition. ${ }^{14,15}$

\section{Pathogenesis:}

The thyrotoxic crisis typically occurs in patients in whom preexisting hyperthyroidism has not been diagnosed or has been treated insufficiently. The crisis has an abrupt onset, and is almost always evoked by a precipitating factor. How such precipitating events result in an accentuation of thyrotoxicosis is unclear. The magnitude and the steepness of the hormone increase may be more important than the absolute values of circulating TH's levels. ${ }^{12,16}$ Other possible mechanisms explaining the progression from uncomplicated thyrotoxicosis to thyroid storm include an increase of tissue iodothyronine levels or an enhancement of the cellular response to $\mathrm{TH}$.

It is known that $\mathrm{TH}$ increase cellular adrenoceptor expression or modify postreceptor pathways leading to a tissue hypersensitivity to catecholamines. ${ }^{18,19}$

\section{Clinical presentation:}

The clinical picture of the thyroid storm is characterized by four main features: (1) Fever 20,21 , (2) sinus tachycardia or a variety of supraventricular arrhythmias (paroxysmalatrial tachycardia, atrial flutter and atrialfibrillation), often accompanied by various degrees of congestive heart failure ${ }^{17,22}$, (3) central nervous system symptoms (agitation, restlessness, confusion, delirium andcoma) $)^{13-25}$, and finally (4) gastrointestinal symptoms, in particular vomiting, diarrhea, intestinal obstruction. ${ }^{26,27}$ Unexplained jaundice is suggestive for thyroid storm, but is a poor prognostic sign. ${ }^{13,28}$ Dehydration with electrolytes imbalance is another frequent feature. Other typical symptoms and signs of thyrotoxicosis may complete the clinical presentation (goiter, ophtalmopathy, tremor, hyperreflexia, Plummer's nail, systolic hypertension). Younger patients often present sympathetic related symptoms, while older one frequently show cardiovascular dysfunctions. ${ }^{29}$ Atypical presentations,such as normothermic crisis, hepatic failure or apathetic storm (extreme weakness) have been reported. ${ }^{30}$

\section{Diagnosis:}

Thyroid storm is not an entity distinct from thyrotoxicosis, but rather one end of a spectrum of severity of hyperthyoridism. ${ }^{31}$ Since it is difficult in most emergency departments to obtain rapid confirmatory laboratory or nuclear medicine tests, the diagnosis of thyrotoxic crises is often made on the basis of clinical findings alone, even if the symptoms and signs may not be specific. Furthermore, low levels of thyroid stimulating hormone(TSH) and high levels of free triiodothyronine(T3) and free L-thyroxine (T4)are characteristic, but as yet stated, not helpful in distinguishing uncomplicated thyrotoxicosis from thyroid storm. ${ }^{13,32}$

\section{Management:}

Patients with thyroid storm should be treated in the ICU. This allows close cardiac and neurologic monitoring and early recognition of dehydration, cardiac dysrhythmias, heart failure, and respiratory failure. The use of pharmacologic agents to inhibit thyroid hormone synthesis is the primary specific treatment of thyroid storm. Lugol's iodine solution is administered as adjunctive therapy to block release of this stored hormone. Other iodine containing agents, such as the oral radiocontrast agent sodium ipodate, oral potassium iodide solution, or IV sodium iodide, can also be used for this purpose. It is important not to administer any of these iodine containing preparations until at least $1 \mathrm{~h}$ after propylthiouracil has been started. If iodine is given first, it will augment thyroid hormone synthesis. $\beta$-Adrenergic blocking drug(propranolol) is routinely administered to patients with thyroid storm. It blunts the cardiovascular effects of thyrotoxicosis, including tachycardia and hypertension. If there are relative contraindications to propranolol, a cardioselective $\beta$-blocker (eg, metoprolol) may be employed. Propranolol, sodium ipodate, and corticosteroids are known to inhibit conversion of $\mathrm{T} 4$ 
to T3 in peripheral tissues. Routine hydrocortisone administration has been recommended in thyroid storm because of the possibility of coexisting adrenal insufficiency. ${ }^{1,33}$

\section{Acute adrenal insufficiency:}

Cortisol is the predominant corticosteroid secreted from the adrenal cortex in humans.

With severe infection, trauma, burns, illness, or surgery, there is an increase in cortisol production by as much as a factor of six that is roughly proportional to the severity of the illness. ${ }^{34-37}$ Stimulation of the hypothalamic-pituitary-adrenal axis in this contextis caused by elevated levels of circulating cytokines, among other factors. ${ }^{38}$ Adrenal responsiveness to exogenous corticotropin is normally maintained duringacute illness. ${ }^{39-40}$ In addition, during critical illness, levels of corticosteroid binding globulin decrease rapidly, ${ }^{41}$ leading to increased levels of circulating free corticosteroids. Levels of free cortisol may also increase at sites of inflammation owing to the cleavage of corticosteroid-binding globulin by neutrophil elastase, an effect that liberates cortisol. ${ }^{42}$ In addition to having systemic actions, inflammatory cytokines can increase tissue cortisol levels through changes in peripheral cortisol metabolism ${ }^{43}$ and can increase the affinity of glucocorticoid receptors for cortisol. ${ }^{44}$ These changes in cortisol action appear to be important adaptive mechanisms regulating the inflammatory response. ${ }^{45}$ During severe illness, many factors can impair the normal corticosteroid response. These factors include preexisting conditions affecting the hypothalamicpituitary-adrenal axis, ${ }^{45}$ but corticosteroid insufficiency can also occur during the course of acute illness. Responses involving corticotropin-releasing hormone and corticotrophin can be impaired by head injury, central nervous system depressants, or pituitary infarction. ${ }^{45}$

\section{Management:}

Since adrenal insufficiency appears to be common in patients with septic shock, treatment should be initiated at the time of diagnostic testing and can be stopped if results do not indicate the presence of adrenal insufficiency.

In patients in whom improved outcomes are seen, high doses of corticosteroids may be required to overcome tissue specific resistance to corticosteroids. ${ }^{55}$
Supraphysiologic doses of glucocorticoids in patients with critical illness outside the situations in which benefit has been proved are not indicated.

Table-III

Features Suggesting Corticosteroid Insufficiency.

\author{
Symptoms \\ Weakness and fatigue \\ Anorexia, nausea, vomiting \\ Abdominal pain \\ Myal gia or arthralgia \\ Postural dizziness \\ Craving for salt \\ Headaches \\ Memory impairment Depression
}

Findlings on physical examination

increased pigmentation

Hypotension (postural)

Tachycardia

Fever

Decreased body hair

Vitiligo

Features of hypopituitarism

Arnenorrhea

Intolerance of cold

\section{Clinical problems}

Hemodynamic instability

Hyperdynamic (common)

Hypodynamic (rare)

Ongoing inflammation with no obvious source

Multiple organ dysfunction

Hypoglycemia

\section{Laboratory findings}

Hyponatremia

Hyperkalemia

Hypoglycemia

Eosinophilia

Elevated thyrotropin levels 


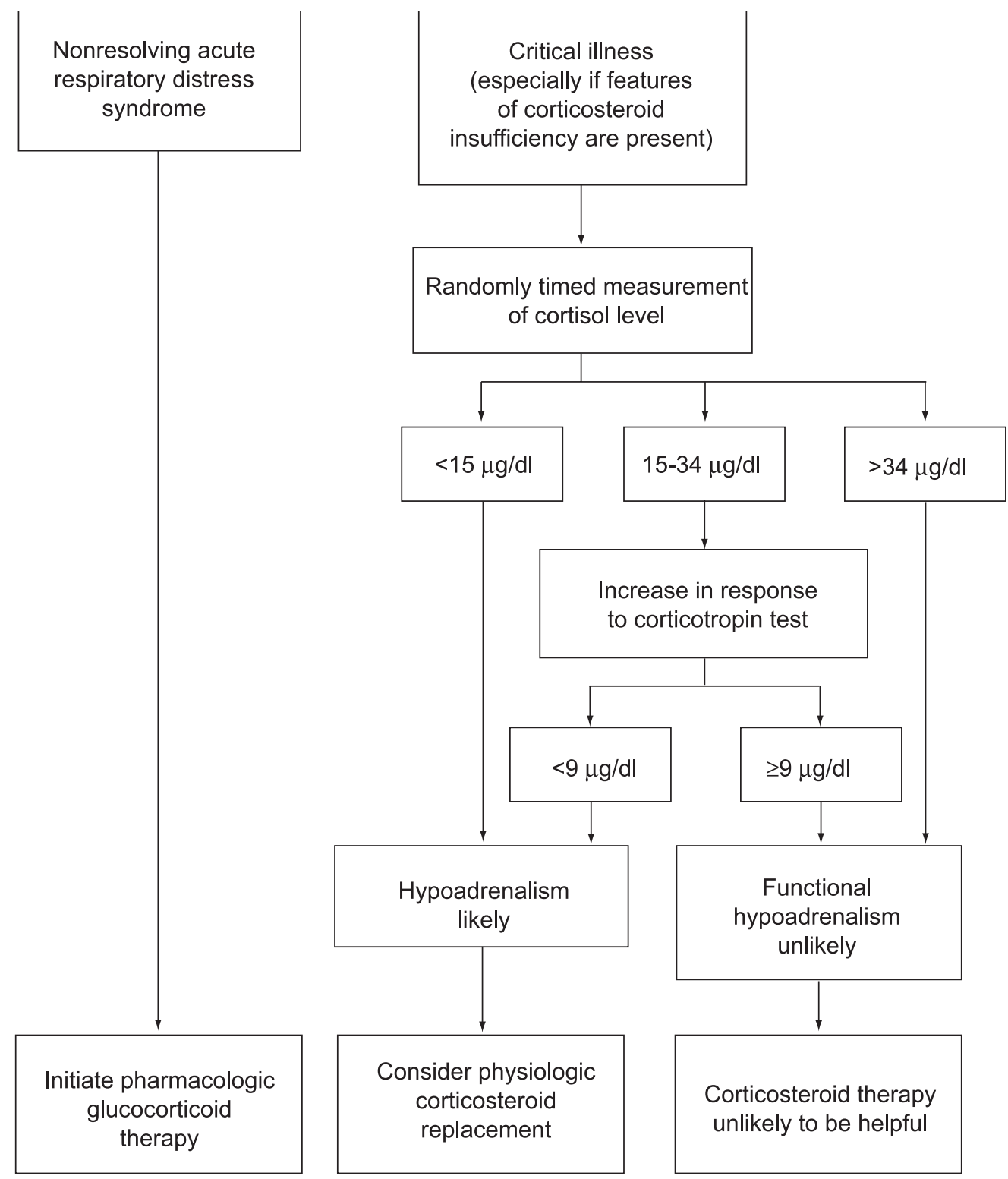

Fig.-2: Investigation of Adrenal Corticosteroid Function in Critically Ill Patients on the Basis of Cortisol Levels and Response to the Corticotropin Stimulation. Test REF: Cooper et al ${ }^{46}$

\section{Myxedema coma:}

Myxedema coma is a severe and life threatening form of decompensated hypothyroidism with an underlying precipitating factor. The mortality rates may be as high as $25-60 \%$ even with best possible treatment ${ }^{56-60}$. It presents as central nervous system dysfunction, defective thermoregulation, and cardiopulmonary decompensation.

\section{Etilogy:}

Myxedema most commonly develops in patients with neglected, inadequately treated, or undiagnosed hypothyroidism. Multiple factors appear to precipitate myxedema coma, including gastrointestinal bleeding; infection; metabolic disturbances such as acidosis, hypoxemia, and hypercapnia; stroke; and cardiovascular compromise (Table 5). 
Table-IV

Common Precipitating Factors of Myxedema Coma ${ }^{61}$

\begin{tabular}{ll}
\hline Stroke & Amiodarone \\
Congestive heart failure & Lithium \\
Surgery & Sedatives \\
Trauma & Metabolic disturbances \\
Gastrointestinal bleeding & Hypoglycemia \\
Infections & Hypoxemia \\
Drugs & Acidosis \\
Anesthetics & Hypercapnia \\
\hline
\end{tabular}

\section{Table-V}

\section{Clinical and laboratory features of myxedema coma}

Respiratory :
Hypoxia
Hypercarbia
Myxedema of larynx
Pleural effusion
Pneumonia (precipitating factor)

\section{Cardiovascular:}

Bradycardia and hypotension

Cardiomegaly

Low cardiac output

Pericardial effusion

Bundle

Cardiogenic shock

Bundle branch blocks and arrhythmias Nonspecific ECG finding

\section{Metabolic:}

Hypothermia

Hypoglycemia
Neuropsychiatric:

Confusion and obtundation

Lethargy

Coma

Seizures

Poor cognitive function

Depression and psychosis

Renal and water metabolism:

Anasarca and hyponatremia

Bladder atony

Urine sodium normal or increased

Urine osmolality > serum osmolality

Gastrointestinal :

Anorexia and nausea

Abdominal pain

Constipation

Paralytic ileus

Toxic megacolon

Gastric atony

Neurogenic oropharyngeal dysphagia

\section{Treatment of Myxedema Coma:}

Treatment should be prompt and multidimensional with attention to the following principles:

(a) intensive care treatment with ventilator support, centralvenous pressure monitoring, and pulmonarycapillary wedge pressure if feasible in patients with cardiac disease,

(b) appropriate fluid management and correction of hypotension and dyselectrolytemia, (c) aggressive management of precipitating factors and steroid supplementation if required,

(d) thyroid hormone replacement. ${ }^{61}$

\section{Pituitary apoplexy:}

Pituitary apoplexy is an uncommon event heralded by abrupt onset of severe headache, restriction of visual fields, deterioration of visual acuity, and weakness of ocular motility frequently coupled with clinical indications of decreased endocrine function. 
Hemorrhage into or necrosis of a preexisting sellar mass, usually a pituitary macroadenoma,produces an expansion of sellar contents. Compression of adjacent structures elicits the variable expression of symptoms referable to displacement of the optic nerves and chiasm and impingement of the third, fourth, and sixth cranial nerves. Damage to or destruction of the anterior pituitary leads to multiple acute and/or chronic hormone deficiencies in many patients. ${ }^{63}$

Signs and symptoms of pituitary apoplexy

- Headache (frontal or retroorbital)

- Restriction of visual fields

- Decrease in visual acuity

- Ophthalmoplegia

- Nausea

- Vomiting

- Vertigo

- Meningismus

- Decreased level of consciousness

- Facial pain or altered or impaired facial sensation

- Epilepsy

- Fever

- Hemiparesis

- Horner syndrome

\section{TREATMENT}

The pituitary gland remains capable of secreting adequate amounts of hormones when as little as $10 \%$ of residual tissue remains; however, a dearth or absence of sufficient hormone can lead to adrenal crisis. The definitive treatment for pituitary apoplexy is surgery for decompression of constricted cavernous and/or suprasellar structures, especially in cases in which visual acuity or field defects, decreased level of consciousness,or progressive deterioration of visual or oculomotor abilities are present. A significant visual compromise, diminished level of consciousness, and declining visual status are clear indications for operative intervention. ${ }^{64}$ Extensive intracavernous extension or invasion limit the opportunity for complete tumor removal. Medical management includes close monitoring of endocrine, neurological, and ophthalmological function, hormone administration, and support with intravenous fluids and electrolytes.

\section{Conclusion:}

Endocrine emergencies are life threatening as well as uncommon. Timely diagnosis is the greatest challenge for the physician and intensivist. Prompt recognition and management is mandatory to avoid their dreadful consequences. A brief clinical history, suspicion through experienced clinical eye can be helpful to manage the patient before it brings fatal complications. Laboratory investigation helps the confirmation of the clinical suspicion to become a diagnosis but that is also time consuming and very difficult for health facilities in a country like Bangladesh.

\section{Reference:}

1. Kruse J. A., Endocrine Emergencies, ACCP Critical Care Board Review 2003:87-96

2. Bajwa SS, Ravi Jindal R. : Endocrine emergencies in critically ill patients: Challenges in diagnosis and management. Indian Journal of Endocrinology and Metabolism. 2012;16 : 5:722-727.

3. Goldberg PA, Inzucchi SE. Critical issues in endocrinology. Clin Chest Med. 2003;24:583-606.

4. Ennis ED, Stahl E, Kreisberg RA. The hyperosmolar hyperglycemic syndrome. Diabetes Rev 1994;2:115-26.

5. Umpierrez GE, Khajavi M, Kitabchi AE. Review: diabetic ketoacidosis and hyperglycemic hyperosmolar nonketotic syndrome. Am J Med Sci 1996;311: 225-33.

6. Ennis ED, Kreisberg RA. Diabetic ketoacidosis and the hyperglycemic hyperosmolar syndrome. In: LeRoith D, Taylor SI, Olefsky JM, editors. Diabetes mellitus. A fundamental and clinical text. Philadelphia: Lippincott Williams \& Wilkins; 2000. p. 336-47.

7. Hennis ED, Stahl E, Kreisberg RA. The hyperosmolar hyperglycemic syndrome. Diabetes Rev 1994;2:115.

8. Gonzalez-Campoy JM, Robertson RP. Diabetic ketoacidosis and hyperosmolar nonketotic state: gaining control over extreme hyperglycemic complications. Postgrad Med 1996;99:143-52.

9. Braaten JT. Hyperosmolar nonketotic diabetic coma: diagnosis and management. Geriatrics 1987;42:83-92.

10. American Diabetes Association. Hospital admission guidelines for diabetes mellitus. Diabetes Care 2002;25(Suppl 1):S109.

11. Normal laboratory values. In: Beers MH, Berkow R, editors. The Merck manual of diagnosis and therapy. 17th ed. Whitehouse Station (NJ): Merck \& Co; 1999. Available: www.merck.com/pubs/mmanual/section21/ chapter296/296a.htm (accessed 2003 Feb 28).

12. Tietgens ST, Leinung MC. Thyroid storm. Med Clin North Am 1995; 79: 169-184. 
13. Sarlis JN, Gourgiotis. Thyroid Emergencies. Rev End Metab Dis 2003; 4: 129-136.

14. Gavin LA. Thyroid crises. Med Clin North Am 1991; 75: 179.

15. Gregg-Smith SJ. Thyroid storm following chest trauma. Injury 1993; 6: 422-423.

16. Jacobs HS, Machiedb, Eastman CJ, Ellis SM, Ekinsrp, Mchardy-Young S. Total and free triiodothyronine and thyroxine levels in thyroid storm and recurrent hyperthyroidism. Lancet 1973; 2: 236-238.

17. Coulombe P, Dussault JH, Letarte J, Simmard SJ. Catecholamines metabolism in thyroid diseases.I. Epinephrine secretion rate in hyperthyroidism and hypothyroidism. J Clin Endocrinol Metab 1976; 42: 125131.

18. Bilezikian JP, Loeb JN, Gammon DE. The influence of hyperthyroidism and hypothyroidism on the betaadrenergic responsiveness of the turkey erythrocyte. J Clin Invest 1979; 63(2):184-192.

19. SILVA JE. Catecholamines and the sympathoadrenal system in thyrotoxicosis. In Braveman LE, Utiger Rd, eds. Werner and Ingbar's the thyroid: a fundamental and clinical text. Philadelphia PA: Lippincott Williams and Wilkins, 2000, pp 642-651.73

20. Blum M, Kranjac T, Park CM, Engleman RM. Thyroid storm after cardiac angiography with iodinated contrast medium. Occurrence in a patient with a previously euthyroid autonomous nodule of the thyroid. JAMA 1976; 235: 2324-2325.

21. Simon HB, Daniels GH. Hormonal hyperthermia: endocrinologic causes of fever. Am J Med 1979; 66: 257-263.

22. Coulombe P, Dussault JH, Walker P. Catecholamines metabolism in thyroid diseases. II. Norepinephrine secretion rate in hyperthyroidism and hypothyroidism. J Clin Endocrinol Metab 1977; 44: 1184-1189.

23. HOWTON JC. Thyroid storm presenting as coma. Ann Emerg Med 1988; 17: 343-345.

24. SERRI O, GAGNON RM, GOULET Y, SOMMA M. Coma secondary to apathetic thyrotoxicosis. Can Med Assoc J 1978; 119: 605-607.

25. Modignani RL, VENEGONI M, BERETTA F, FASSINA S. Thyroid storm with encephalopathic symptoms due to Graves' disease and inappropriate secretion of thyrotropin. Ann Ital Med Int 1992; 7: 250- 254.

26. Bhattacharyya A, Wiles PG. Thyrotoxicosis crisis presenting as acute abdomen. J R Soc Med 1997; 90: 1143-1146

17. Cansler CL, Latham JA, Brown PM JR, Chapman WH, Magner JA. Duodenal obstruction in thyroid storm. South Med J 1997; 90: 1143-1146.
28. WARTOFSKY L. Thyroid storm. In: Braveman LE, Utiger Rd, eds. Werner and Ingbar's the thyroid: a fundamental and clinical text. Philadelphia PA: Lippincott Williams and Wilkins, 2000, pp 679- 684.

29. Braveman LE, Utiger RD. Introduction to thyrotoxicosis. In: Braveman LE, Utiger Rd, eds. Werner and Ingbar's the thyroid: a fundamental and clinical text. Philadelphia PA: Lippincott Williams and Wilkins, 1991, pp 654-657.

30. Yin-Zheng J, Hutchinson KA, Bartelloni P, Manthous CA. Thyroid storm presenting as multiple organ dysfunction syndrome. Chest 2000; 118: 877-879

31. Burch HB, Wartofsky L. Life treating thyrotoxicosis. Endocrinol Metab Clin North Amer 1993; 22: 263-277.

32. Ringel MD. Management of hypothyroidism and hyperthyroidism in the intensive care unit. Crit Care Clin 2001; 17: 59-74.

33. Migneco A, Ojetti V, Testa A, Lorenzo A,Silveri NG. Management of thyrotoxic crisis. European Review for Medical and Pharmacological Sciences.2005; 9: 69-74

34. Esteban NV, Loughlin T, Yergey AL, et al.Daily cortisol production rate in man determinedby stable isotope dilution/mass spectrometry.J Clin Endocrinol Metab 1991;72:39-45.

35. Barton RN, Stoner HB, Watson SM. Relationshipsamong plasma cortisol, adrenocorticotrophin,and severity of injury in recentlyinjured patients. J Trauma 1987;27: 384-92.

36. Chernow B, Alexander HR, SmallridgeRC, et al. Hormonal responses to gradedsurgical stress. Arch Intern Med 1987;147:1273-8.

37. Perrot D, Bonneton A, Dechaud H, MotinJ, Pugeat M. Hypercortisolism in septic shockis not suppressible by dexamethasone infusion.Crit Care Med 1993;21:396-401.

38. Chrousos GP. The hypothalamic-pituitary-adrenal axis and immune-mediatedinflammation. N Engl J Med 1995;332:1351-62.

39. Lamberts SWJ, Bruining HA, de JongFH. Corticosteroid therapy in severe illness.N Engl J Med 1997;337: 1285-92.

40. Burchard K. A review of the adrenal cortexand severe inflammation: quest of the "eucorticoid" state. J Trauma 2001;51:800-14.

41. Beishuizen A, Thijs LG, Vermes I. Patternsof corticosteroid-binding globulin andthe free cortisol index during septic shockand multitrauma. Intensive Care Med 2001; 27:1584-91.

42. Hammond GL, Smith CL, Paterson NA,Sibbald WJ. A role for corticosteroid-bindingglobulin in delivery of cortisol to activatedneutrophils. J Clin Endocrinol Metab 1990;71:34-9. 
43. Cooper MS, Bujalska I, Rabbitt E, et al.Modulation of 11b-hydroxysteroid dehydrogenaseisozymes by proinflammatory cytokinesin osteoblasts: an autocrine switchfrom glucocorticoid inactivation to activation.J Bone Miner Res 2001;16:1037-

44. Franchimont D, Martens H, HagelsteinMT, et al. Tumor necrosis factor alphadecreases, and interleukin-10 increases, thesensitivity of human monocytes to dexamethasone:potential regulation of the glucocorticoid receptor. J Clin Endocrinol Metab 1999; 84:2834-9.

45. Ten S, New M, Maclaren N. Clinicalreview 130: Addison's disease 2001. J ClinEndocrinol Metab 2001;86:2909-22.

46. Cooper M S, Stewart P M. Current concepts Corticosteroid Insufficiencyin Acutely Ill Patients. The new england journal of medicine. 2003;348: 727-34.

55. Meduri GU, Tolley EA, Chrousos GP,Stentz F. Prolonged methylprednisolone treatmentsuppresses systemic inflammation inpatients with unresolving acute respiratorydistress syndrome: evidence for inadequate endogenous glucocorticoid secretion and inflammationinduced immune cell resistanceto glucocorticoids. Am J Respir Crit CareMed 2002; 165: 983-91.

56. L. Wartofsky, “Myxoedema coma,” Endocrinology Metabolism Clinics of North America, vol. 35, pp. 687698, 2006.

57. I. Rodr'ýguez, E. Fluiters, L. F. P'erez-M'endez, R. Luna, C. P'aramo, and R. V. Garc'ýa-Mayor, "Factors associated with mortality of patients with myxoedema coma: prospective study in 11 cases treated in a single institution,” Journal of Endocrinology, vol. 180, no. 2, pp. 347-350, 2004.

58. T. Yamamoto, J. Fukuyama, and A. Fujiyoshi, "Factors associated with mortality of myxedema coma: report of eight cases and literature survey,” Thyroid, vol. 9, no. 12, pp. 1167-1174, 1999.

59. P. Dutta, A. Bhansali, S. Masoodi, S. Bhadada, N. Sharma, and R. Rajput, "Predictors of outcome in myxoedema coma: a study from a tertiary care centre,” Critical Care, vol. 12, no. 1, p. R1, 2008.

60. W. Reinhardt and K. Mann, "Incidence, clinical picture, and treatment of hypothyroid coma: results of a survey," Medizinische Klinik, vol. 92, pp. 521-524, 1997.

61. Gardner DG. Endocrine emergencies. In: Gardner DG, Shoback D, editors. Greenspan's basic and clinical endocrinology. 8th ed. New York: McGraw-Hill; 2007:868-93.

62. Mathew V, Misgar RA, Ghosh S, Mukhopadhyay P, Roychowdhury P, Pandit K, Mukhopadhyay S, and Chowdhury S. Myxedema Coma: A New Look into an Old Crisis. Journal of Thyroid Research.2011:1-7.

63. VERREES M., ARAFAH B. M., SELMAN W. R. Pituitary tumor apoplexy: characteristics, treatment, and outcomes. Neurosurg.Focus 2004;16: 1-7

64. Cardoso ER, Peterson EW: Pituitary apoplexy: a review. Neurosurgery.1984;14:363-373. 